\title{
EEE
}

Homepage: http://publisher.uthm.edu.my/proceeding/index.php/eeee e-ISSN : 2756-8458

\section{Effect of Hot Spot Temperature to the Temperature and Current Distribution in Transformer-Oil Based Nanofluids}

\author{
A. F. R. Azzam ${ }^{1}$, N. A. Othman ${ }^{1 *}$, R. A. Rahman $^{1}$, H. \\ Kamarden $^{2}$
}

${ }^{1}$ Department of Electrical Power Engineering, Faculty of Electrical \& Electronic Engineering, Universiti Tun Hussein Onn Malaysia (UTHM), 86400 Batu Pahat, MALAYSIA

${ }^{2}$ School of Electrical Engineering, Faculty of Engineering, Universiti Teknologi Malaysia (UTM), 81310 Johor Bahru, Johor, MALAYSIA

DOI: https://doi.org/10.30880/eeee.2020.01.01.002

Received 13 August 2020; Accepted 06 September 2020; Available online 30 October 2020

\begin{abstract}
Heat transfer coefficient must be in adequate level to ensure the transformer oil is in good condition. The presence of power losses in the core and windings in the form of heat may cause the transformer oil to deteriorate easily. Continuous monitoring of transformer heat distribution could provide useful information on the hot spot temperature (HST) development. Therefore, this paper simulates a 30MVA Oil Natural Air Natural (ONAN) transformer temperature distribution pattern with and without HST. This study aims to observe the effect of three different HST values located at the top of HV winding on the temperature distribution. Next, the correlation between temperature and current distribution with the presence of HST was also included. Mineral oil and transformer oil-based $\mathrm{Al}_{2} \mathrm{O}_{3}$ nanofluid was used in this study to determine transformer oil with better heat transfer coefficient in convection process. Results show that the presence of HST causes an increased in temperature distribution at the top of the transformer. It is also evident that the usage of transformer oil-based $\mathrm{Al}_{2} \mathrm{O}_{3}$ nanofluid improves overall heat transfer characteristics of the base fluid. Also, it is found that the temperature and current distribution pattern was similar that indicates a correlation between both parameters.
\end{abstract}

Keywords: Nanofluids, Hot Spot Temperature, Current Distribution, Temperature Distribution

\section{Introduction}

Transformers can be considered as the most useful static device that works on the principles of electromagnetic induction. A transformer is an electrical device that transfers electrical power from one electric circuit to another without changing its frequency. In simple words, transformers serve to increase or decrease alternating current (AC) voltage. The transformer core is used to provide a controlled path for the magnetic flux generated in the transformer. The magnetic flux is generated by the current that flows through the windings or also referred to as coils. Historically, the apparatus of 
electromagnetic-induction constructed by Michael Faraday in the year 1831 contained all basic elements of transformers particularly two independent coils and a closed iron core [1]. In the year 1886, William Stanley introduced the first transformer for commercial used. The efficiency of this machine is generally higher than $95 \%$ since there is no moving part in the transformer [2].

Large transformers are then introduced with transformer oil-filled that cools and insulates the windings. The transformer oil-filled was introduced to overcome the heat dissipation problem in high rated transformer. This is because the failure of transformer to dissipate heat may reduce the lifespan of transformer [2]. George Westinghouse is the person who immerse the entire transformer in a tank of oil and spaced the laminations in the core so that the oil could circulate by convection among them [1]. Convection process is important in cooling the transformer along with conduction process. Almost all oil immersed type of transformer will undergoe convection process especially for Oil Natural Air Natural (ONAN) and Oil Natural Air Forced (ONAF) transformer.

Nowadays, transformer oil is generally made of highly refined mineral oil. Mineral oil has good electrical and cooling properties that able to cool the windings and insulation of the transformer tank. The mineral oil circulates inside the transformer and absorb heat from the transformer interior via conduction process. Although the convection process occurs inside the transformer, there may be some areas inside the transformer that fail to dissipate heat which causes the heat to be accumulated in the transformer. Hence, if this condition continues for some period of time, it may eventually reduce the lifespan of the transformer radically. Therefore, this paper simulates the heat distribution pattern produced by working transformer in the absence and presence of HST using finite element software.

\section{Materials and Methods}

\subsection{Transformer model}

A 30MVA ONAN transformer was modelled in QuickField software to determine the thermal properties of the transformer. A two dimensional (2D) model of transformer is developed based on a transformer cross-sectional shown in Figure 1. It is important to note that the transformer temperature distribution in this work is measured only at the top part of the transformer tank. This is due to the movement of hot oil at the top part of the transformer tank while cool oil moves to the bottom part of the transformer tank as the movement of oil circulating inside the transformer.

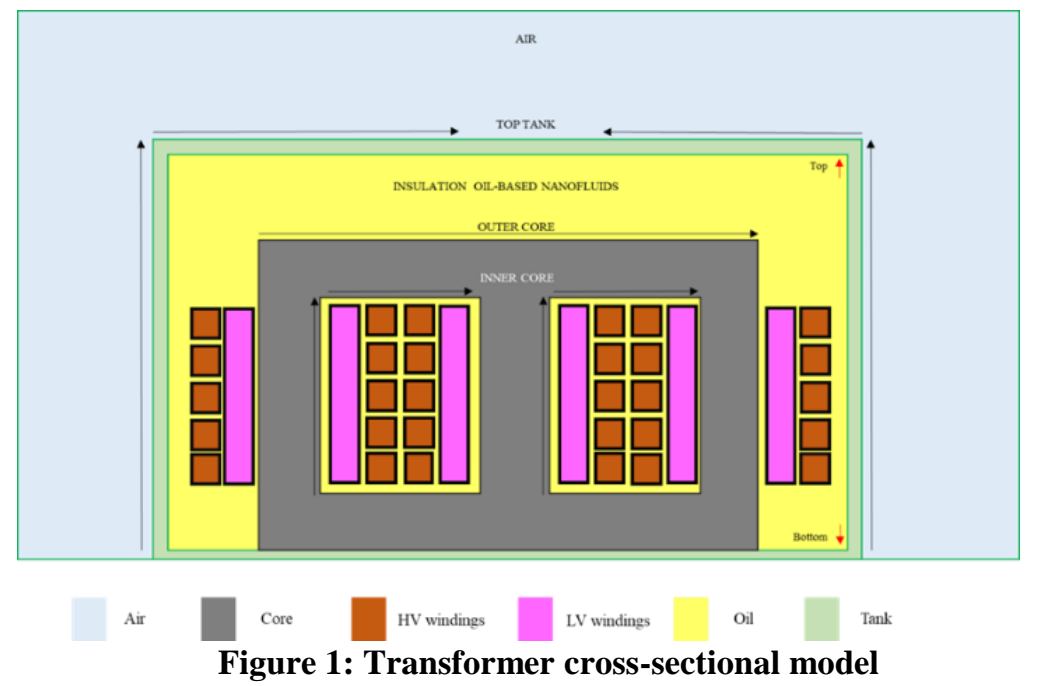

2.2 Simulation Parameters

The material properties of the transformer and their corresponding thermal conductivities listed in Table 1 were inserted manually to the model drawn in QuikField software for simulation as shown in 
Figure 2. To evaluate the thermal behavior of nanofluids as cooling mechanism in a transformer, $\mathrm{Al}_{2} \mathrm{O}_{3}$ nanofluid was chosen as the insulation oil in this study.

Table 1: Transformer simulation parameters

\begin{tabular}{ccc}
\hline Transformer Parts & Material & Thermal conductivity $\left(\mathrm{W} / \mathrm{m}^{*} \mathrm{~K}\right)$ \\
\hline \hline Air & Air & 0.0181 \\
Insulation oil & Mineral oil & 0.162 \\
Insulation oil & $\mathrm{Al}_{2} \mathrm{O}_{3}$ nanofluid & 0.22109 \\
Core & Silicon Steel & 31 \\
Windings & Aluminium 2024-T6 & 110 \\
Transformer Tank & Steel & 43 \\
\hline
\end{tabular}

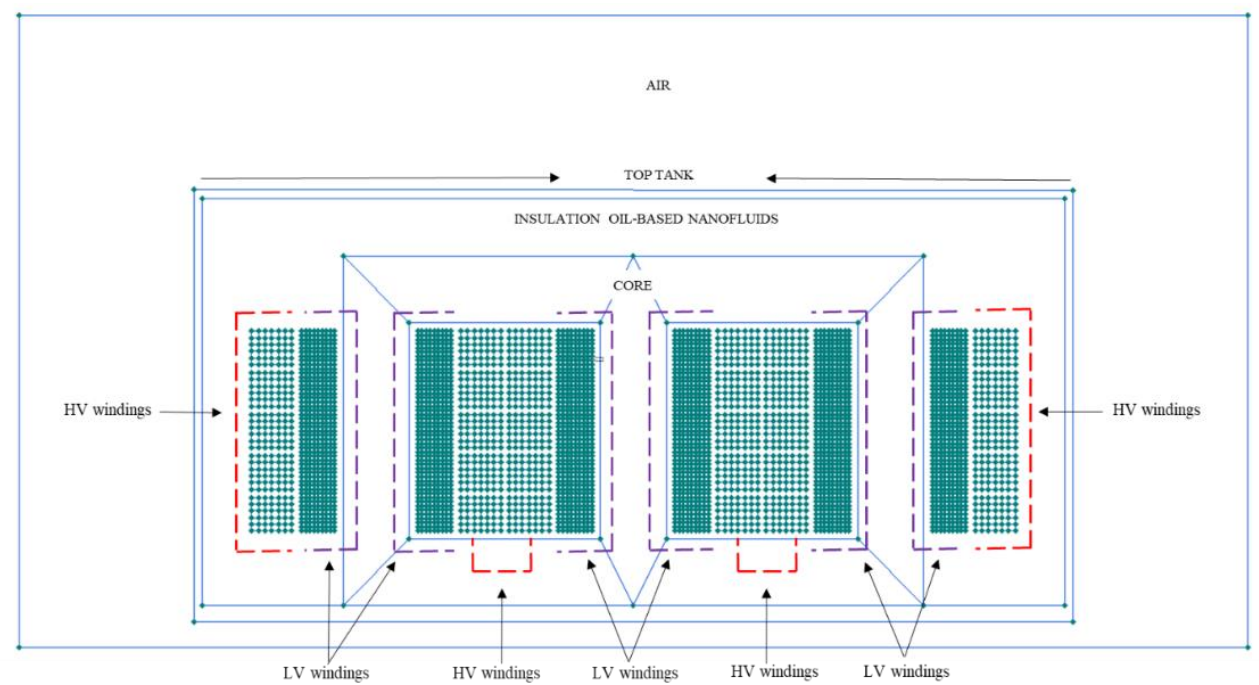

Figure 2: Transformer model with winding using quickfield software

Table 2 tabulates the value of hot spot temperature (HST) that had been used in this works. Different value of HST is used on the HV winding in order to indicate the effect of HST on temperature distribution at the top tank of the transformer.

Table 2: Difference value of HST at the top of $\mathrm{HV}$ winding

\begin{tabular}{cc}
\hline Transformer condition & Hot spot temperature \\
\hline \hline Hot spot A (HST A) & $100^{\circ} \mathrm{C}[2]$ \\
Hot spot B (HST B) & $110^{\circ} \mathrm{C}[3]$ \\
Hot spot C (HST C) & $140^{\circ} \mathrm{C}[4]$ \\
\hline
\end{tabular}

\section{Results and Discussion}

The simulation results for heat distribution of 30MVA transformer at normal working condition (without HST) is illustrated in Figure 3. From the figure, it is proven that the hottest part is found in the winding area compared to other part of the transformer. The heat is believed to be transferred in different ways in order to cool the transformer via conduction, radiation and convection. Conduction process occurs when the heat is transferred to the oil that surrounds the core and windings and it was conducted at the walls of the transformer tank. Meanwhile, convection and radiation process occurs when the heat is transferred to the surrounding [5].

Figure 4 depicts the comparison of temperature distribution between transformer oil-based $\mathrm{Al}_{2} \mathrm{O}_{3}$ nanofluid and mineral oil under normal working conditions. Based on the observation from Figure 4, there are clear differences in temperature distribution approximately $3.8 \%$ between these two types of 
insulating oils. The highest temperature for both oils recorded was in the middle of the tank. This results supports the theory that the temperature pattern is downward due to the heat being accumulated in the middle of the tank as stated in [6]. Mineral oil recorded the maximum reading of temperature at $58.3^{\circ} \mathrm{C}$ while transformer oil-based $\mathrm{Al}_{2} \mathrm{O}_{3}$ nanofluid is at $60.5^{\circ} \mathrm{C}$. Worth to mention that the curve graph also shows the minimum temperature distribution for both insulating oil. The minimum temperature for mineral oil is at $56.1^{\circ} \mathrm{C}$ while $58.3^{\circ} \mathrm{C}$ for transformer oil-based $\mathrm{Al}_{2} \mathrm{O}_{3}$ nanofluid. According to [5], the heat is accumulated in the middle of tank thus proving that the middle of the tank recorded the maximum temperature while both sides of the transformer tank recorded the minimum temperature.

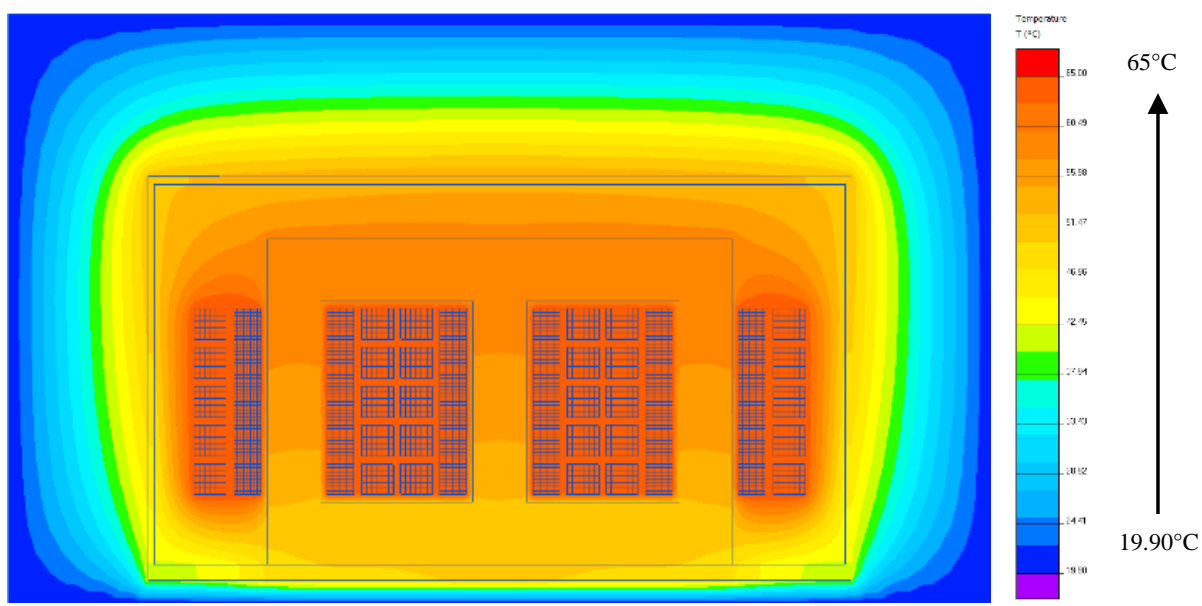

Figure 3: Temperature distribution for 30MVA transformer without HST

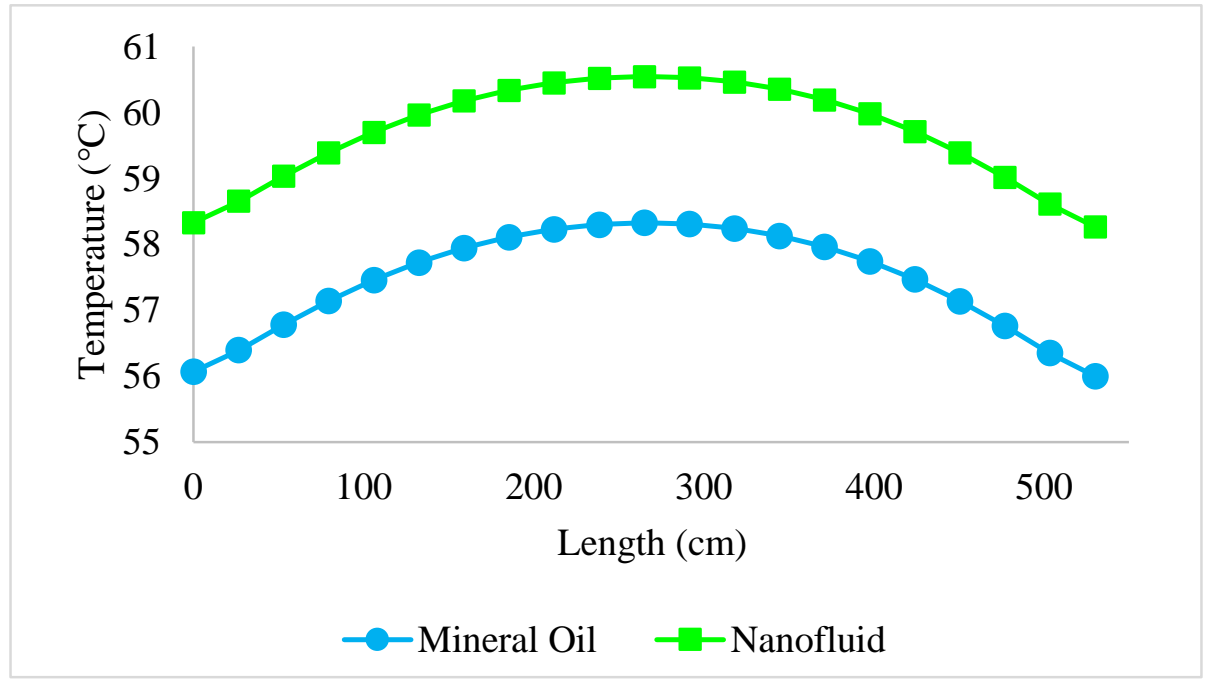

Figure 4: Comparison of temperature distribution between mineral oil and transformer oil-based $\mathrm{Al}_{2} \mathrm{O}_{3}$ nanofluid under normal working condition

3.1 Temperature distribution for 30MVA ONAN transformer with the presence of hot spot temperature (HST)

With the growing capacity of transformer, losses and heat dissipation was also increased. According to researcher [7], the increment of losses and heat dissipation may be worsened with the presence of HST as it can cause degradation of the winding insulation material. Thus, in order to characterize the thermal behavior of the transformer in full capacity, the simulation is conducted with the presence of three different values of $\mathrm{HST}$ which are $100^{\circ} \mathrm{C}, 110^{\circ} \mathrm{C}$ and $140^{\circ} \mathrm{C}$. All of these three HST values had been located only at $1 \mathrm{~cm}$ from the top of $\mathrm{HV}$ winding. Figure 5-7 shows the working of 30MVA ONAN 
transformer with the presence of HST A, HST B and HST C respectively at the top of HV winding. The reason why all HST value is located at top of HV winding is because there is a significant increase when HST is located at the top of HV winding compared to the bottom of HV winding [2, 6-9].

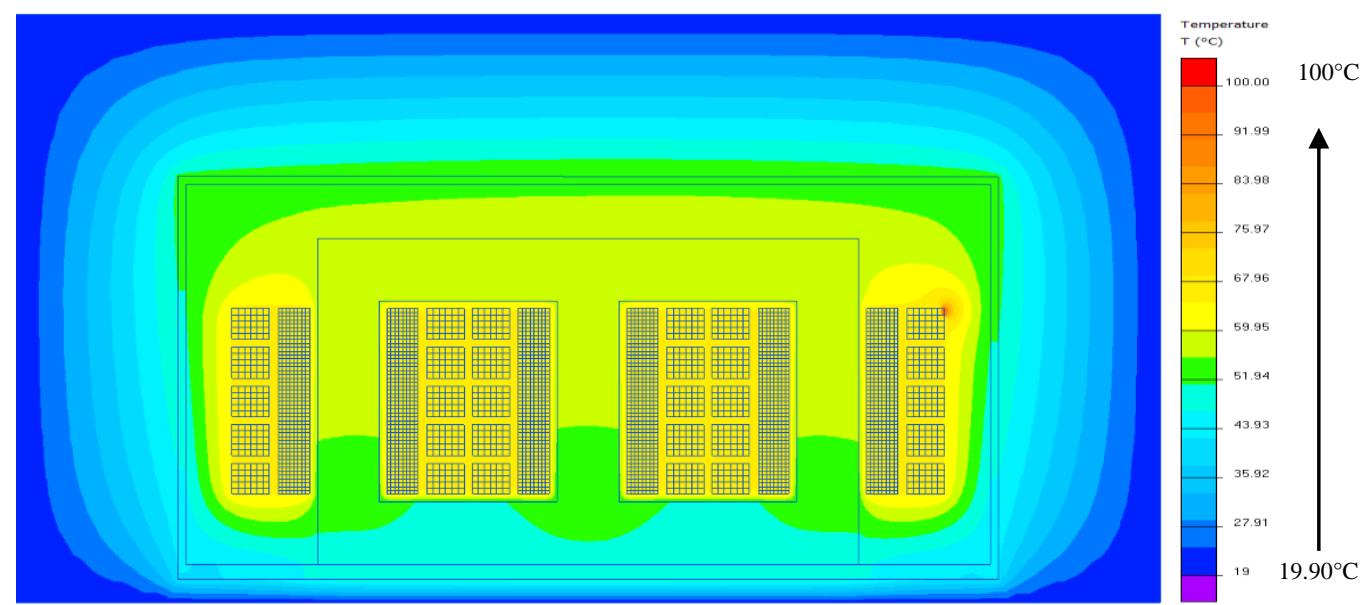

Figure 5: Temperature distribution of transformer with the presence of HST A at the top of HV winding

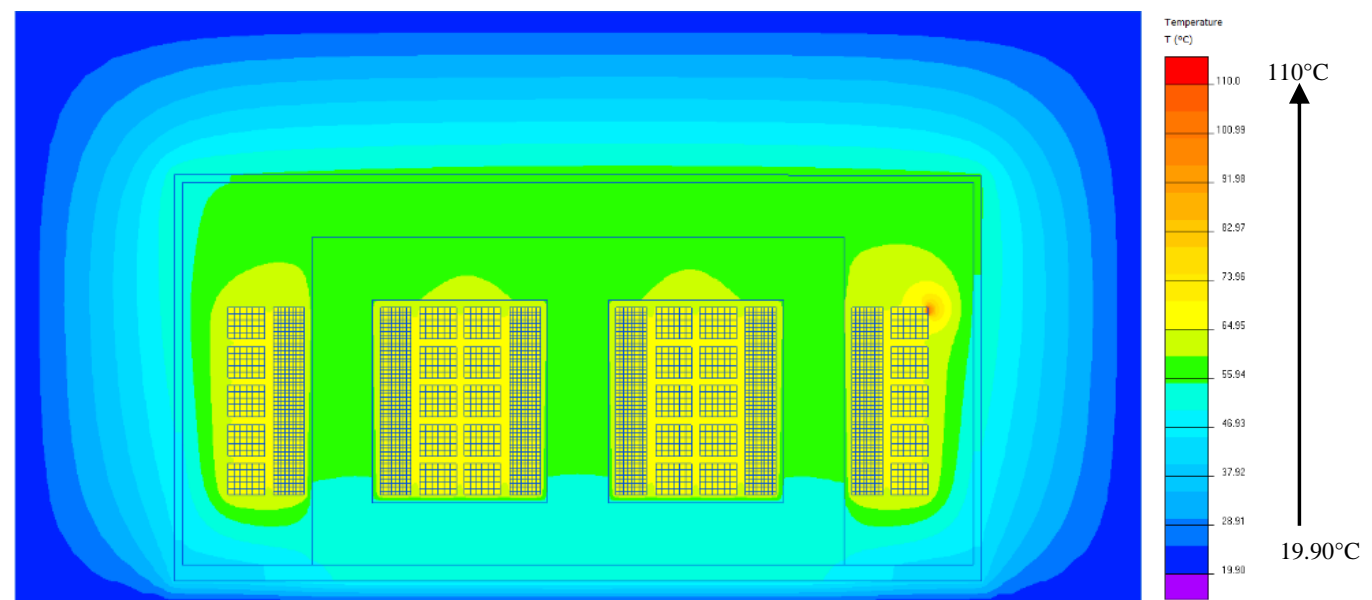

Figure 6: Temperature distribution of transformer with the presence of HST B at the top of HV winding

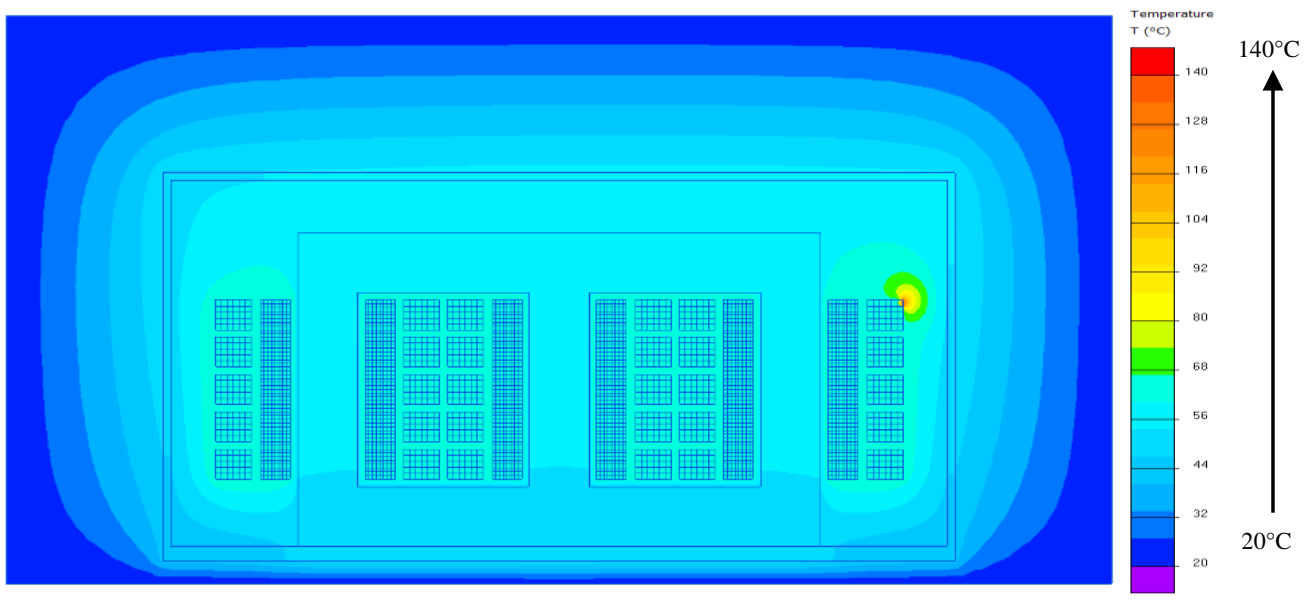


Figure 7: Temperature distribution of transformer with the presence of HST C at the top of HV winding

Figure 8 illustrates the comparison of temperature distribution at the top part of the transformer tank using mineral oil and transformer oil-based $\mathrm{Al}_{2} \mathrm{O}_{3}$ nanofluid with the presence of all HST. From Figure 8 , it can be seen that HST causes an increment in the temperature distribution of the transformer either using mineral oil or transformer oil-based $\mathrm{Al}_{2} \mathrm{O}_{3}$ nanofluid. It also can be concluded from the current finding that the temperature distribution increases with the increase of HST value. Since the HST C is the highest value in this work compared to HST A and HST B which is at $140^{\circ} \mathrm{C}$, the temperature distribution with the presence of HST $\mathrm{C}$ had a considerable increase for both insulating oil.

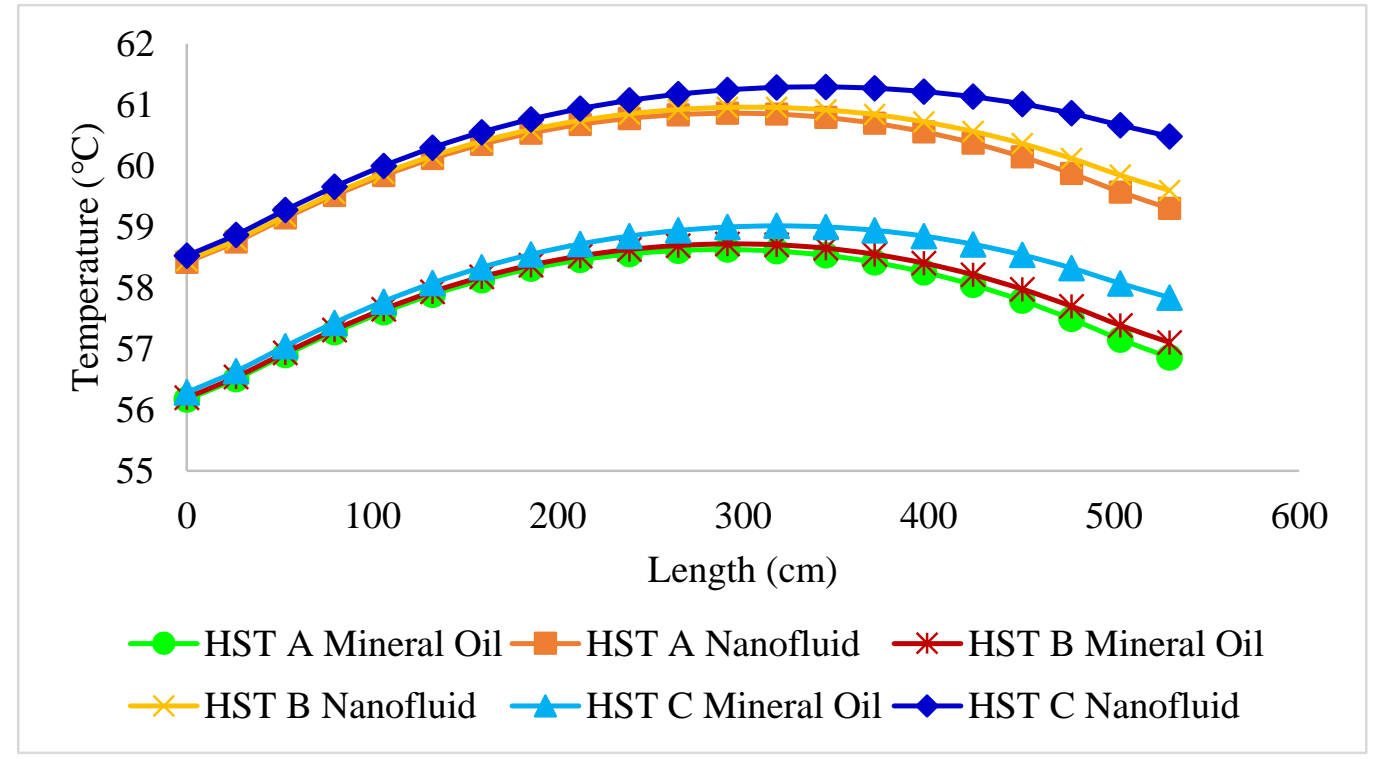

Figure 8: Comparison of temperature distribution at top of transformer tank with the presence of all HST using mineral oil and transformer oil-based $\mathrm{Al}_{2} \mathrm{O}_{3}$ nanofluid

\subsection{Correlation between temperature and current distribution}

Since HST C shows the most significant increase in temperature, the correlation between temperature and current distribution was analyzed only with the presence of HST C. Figure 9 represents the correlation between temperature distribution and current distribution at the top of transformer tank with the presence of HST C using mineral oil and transformer oil-based $\mathrm{Al}_{2} \mathrm{O}_{3}$ nanofluid as insulating oil. As can be seen from Figure 9, the current distribution curve graph can be considered as similar to the temperature distribution at the top of transformer tank. From the presented result, it is observed that current distribution of the transformer is much related with temperature distribution. Thus, it can be concluded that the presence of HST at the HV winding has led to an increase in temperature distribution and also current distribution. 


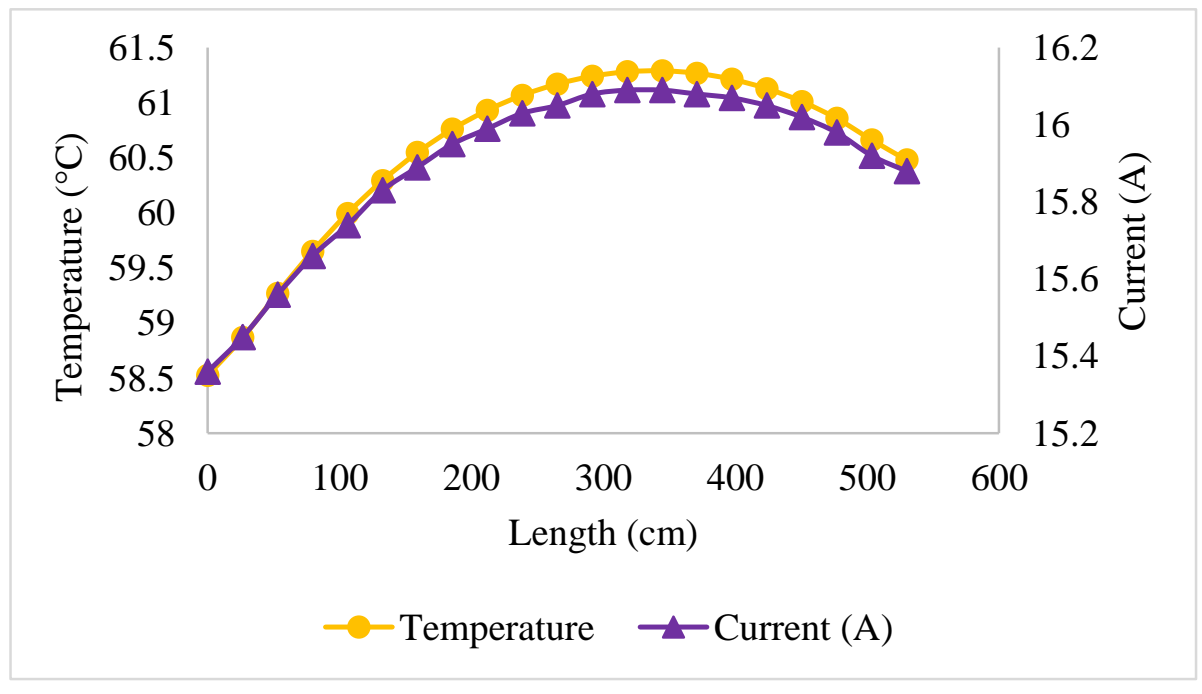

(a)

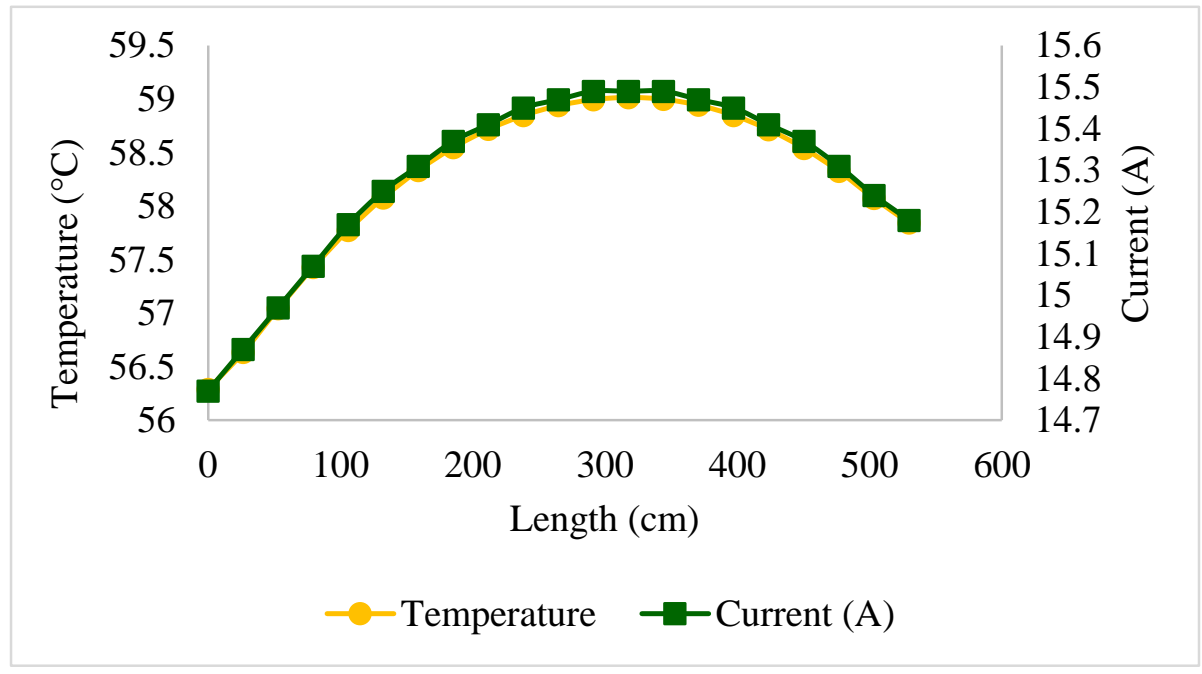

(b)

Figure 9: Correlation between temperature and current distribution with the presence of HST C using (a) mineral oil and (b) transformer oil-based $\mathrm{Al}_{2} \mathrm{O}_{3}$ nanofluid as insulating oil.

According to the nameplate rating of transformer in Table 3, it is generally accepted that the full load current normally at $15.75 \mathrm{~A}$ for mineral oil transformer. But with the presence of HST at the HV winding in transformer oil-based $\mathrm{Al}_{2} \mathrm{O}_{3}$ nanofluid, the value of current seems much higher. Table 4 tabulates the reading of current distribution of transformer with the presence of HST A, HST B and $\mathrm{HST} \mathrm{C}$ at the top of $\mathrm{HV}$ winding using mineral oil and transformer oil-based $\mathrm{Al}_{2} \mathrm{O}_{3}$ nanofluid as insulating oil. It is interesting to note that, when the value of HST exceeds $100^{\circ} \mathrm{C}$ temperature, the current can reach the maximum value of $16.09 \mathrm{~A}$ for transformer oil-based $\mathrm{Al}_{2} \mathrm{O}_{3}$ nanofluid. Meanwhile, the current distribution in mineral oil transformer still below the full load current level.

Table 3: Nameplate rating of the 30MVA ONAN transformer

\begin{tabular}{lcc}
\hline Parameter & Value & Unit \\
\hline \hline Std. specification & IEC 60076-1 & - \\
kVA & 300 & $\mathrm{kVA}$ \\
Phase & 3 & - \\
Frequency & 50 & $\mathrm{~Hz}$ \\
Volts HV & 11000 & $\mathrm{~V}$ \\
(No load) LV & 433 & $\mathrm{~V}$
\end{tabular}




\begin{tabular}{lcc} 
Amps HV & $\mathbf{1 5 . 7 5}$ & $\mathrm{A}$ \\
Amps LV & 400 & $\mathrm{~A}$ \\
No Load Loss & 0.529 & $\mathrm{~kW}$ \\
Load Loss & 3.024 & $\mathrm{~kW}$ \\
Temp. rise Oil/Winding & $60 / 65$ & ${ }^{\circ} \mathrm{C}$ \\
\hline
\end{tabular}

Table 4: The reading of current distribution of transformer with the presence of all HST at the top of $\mathrm{HV}$ winding using mineral oil and transformer oil-based $\mathrm{Al}_{2} \mathrm{O}_{3}$ nanofluid as insulating oil

\begin{tabular}{cccc}
\hline Transformer Condition & $\begin{array}{c}\text { Hot Spot Temperature } \\
\left({ }^{\circ} \mathrm{C}\right)\end{array}$ & $\begin{array}{c}\text { Current }(\mathrm{A}) \\
(\text { Mineral oil) }\end{array}$ & $\begin{array}{c}\text { Current (A) } \\
\left(\mathrm{Al}_{2} \mathrm{O}_{3} \text { nanofluid) }\right.\end{array}$ \\
\hline \hline HST A & $100^{\circ} \mathrm{C}$ & 15.39 & 15.97 \\
HST B & $110^{\circ} \mathrm{C}$ & 15.41 & 16.00 \\
HST C & $140^{\circ} \mathrm{C}$ & 15.49 & 16.09 \\
\hline
\end{tabular}

\section{Conclusion}

This paper presents the simulation of the temperature and current distribution pattern of 30MVA ONAN transformer with three different values of hot spot temperature (HST). Based on the presented results, it can be concluded that the presence of HST at the top of HV winding contributes to the increment of temperature distribution at the top of the transformer tank. As the value of HST become higher, the temperature distribution increases. Moreover, both temperature and current distribution are in an excellent agreement indicating a strong relationship between both parameters with the presence of HST. This study finally concludes that HST does contribute to the overall increase in transformer temperature distribution in both types of insulation oil.

\section{Acknowledgement}

The authors express their sincere gratitude to the Faculty of Electrical and Electronic Engineering, Universiti Tun Hussein Onn Malaysia (UTHM) for the use of facilities and equipment supports.

\section{References}

[1] S. Teszenszky, "History of Transformers," IEEE Power Eng. Rev., vol. 16, no. 12, p. 9, 1996, doi: 10.1109/MPER.1996.546444

[2] M. A. Husin, N. A. Othman, N. A. Muhammad, H. Kamarden, and M. S. Kamarudin, "Top oil heat distribution pattern of ONAN corn oil based transformer with presence of hot spot study using FEMM,” vol. 8, no. 3, pp. 753-760, 2019, doi: 10.11591/eei.v8i3.1602

[3] M. T. Ishak and Z. Wang, "Transformer hotspot temperature calculation using IEEE Loading Guide,” Proc. 2008 Int. Conf. Cond. Monit. Diagnosis, C. 2008, pp. 1017-1020, 2008, doi: 10.1109/CMD.2008.4580455

[4] James H. Harlow, Electric Power Transformer Engineering, Second Edi. Boca Raton, London, New York: CRC Press Taylor \& Francis Group, 2007

[5] M. I. Hasan, "Using the transformer oil-based nanofluid for cooling of power distribution transformer," vol. 8, no. 3, pp. 229-238, 2017

[6] N. A. Muhamad, H. Kamarden, and N. A. Othman, "Heat distribution pattern of oil-filled transformer at different hottest spot temperature locations," Proc. IEEE Int. Conf. Prop. Appl. Dielectr. Mater., vol. 2015-Octob, pp. 979-982, 2015, doi: 10.1109/ICPADM.2015.7295438

[7] L. L. Rui and L. L. Rui, "Heat Transfer Performance of Oil-Based Nanofluids in Electric Transformers By Heat Transfer Performance of Oil-Based Nanofluids in Electric Transformers by," no. January, 2015 
[8] R. Godina, E. M. G. Rodrigues, J. C. O. Matias, and J. P. S. Catalão, Effect of loads and other key factors on oil-transformer ageing: Sustainability benefits and challenges, vol. 8, no. 10. 2015, doi: 10.3390/en81012147

[9] B. S. H. M. S. Y. Matharage, M. A. R. M. Fernando, M. A. A. P. Bandara, G. A. Jayantha, and C. S. Kalpage, "Performance of coconut oil as an alternative transformer liquid insulation," IEEE Trans. Dielectr. Electr. Insul., vol. 20, no. 3, pp. 887-898, 2013, doi: 10.1109/TDEI.2013.6518958 